\title{
Usefulness of complex bacteriological and serological analysis in patients with spondyloarthritis
}

\author{
DANIELA CRISTEA $^{1 *}$, MARIUS TRANDAFIR $^{2,3 *}$, VIOLETA CLAUDIA BOJINCA ${ }^{2,3^{*}}$, \\ ADRIANA SIMONA CIONTEA ${ }^{1 *}$, MELANIA MIHAELA ANDREI $^{1 *}$, ANDREI POPA $^{1 *}$, \\ BRANDUSA ELENA LIXANDRU ${ }^{1 *}$, CORNELIA MADALINA MILITARU $^{1 *}$, ALEXANDRA MARIA NASCUTIU $^{1,2^{*}}$, \\ DENISA PREDETEANU ${ }^{3 *}$, RUXANDRA IONESCU $^{2,3^{*}}$, CLAUDIU POPESCU $^{2,4 *}$, ANI IOANA COTAR ${ }^{1 *}$, \\ MIRCEA IOAN POPA ${ }^{1,2^{*}}$, DEMETRIOS A. SPANDIDOS ${ }^{5 *}$ and IRINA CODITA ${ }^{1,2^{*}}$

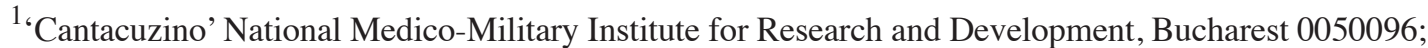 \\ ${ }^{2 ،}$ Carol Davila' University of Medicine and Pharmacy, Bucharest $050474 ;{ }^{3}$ Department of Internal Medicine and Rheumatology, \\ Hospital Sfanta Maria, Bucharest 011172; ${ }^{4}$ 'Dr Ion Stoia' Clinical Center for Rheumatic Diseases, Bucharest 030167, Romania; \\ ${ }^{5}$ Laboratory of Clinical Virology, Faculty of Medicine, University of Crete, 71003 Heraklion, Crete, Greece
}

Received July 25, 2018; Accepted February 14, 2019

DOI: $10.3892 /$ etm.2019.7336

\begin{abstract}
Spondyloarthritis (SpA) is a group of associated chronic systemic inflammatory immune-mediated rheumatic diseases affecting axial and peripheral joints and entheses. The aim of the present study was to identify what parameters are useful to determine in order to better understand the correlation between the disease activity/severity and the microbiological results/immune status against intestinal and/or urogenital pathogens. Microorganisms known to trigger SpA, including Klebsiella spp., Yersinia spp., Salmonella spp., Campylobacter spp. and Chlamydia spp., were analyzed in various specimens (stool, urine, synovial fluid and serum) collected from 27 randomly selected SpA patients and 26 healthy controls using a combined direct and indirect approach relying on conventional culture technique and
\end{abstract}

Correspondence to: Dr Violeta Claudia Bojincă, Department of Internal Medicine and Rheumatology, Hospital Sfanta Maria, Building Ion Mihalache 37-39, Sector 1, Bucharest 011172, Romania E-mail: vmbojinca@yahoo.com

*Contributed equally

Abbreviations: AS, ankylosing spondylitis; ASAS, Assessment of SpondyloArthritis International Society; ASDAS, Ankylosing Spondylitis Disease Activity Score; ATG, anti-thyroglobulin antibodies; ATPO, anti-thyroid peroxidase; BASDAI, Bath Ankylosing Spondylitis Disease Activity Index; BASFI, Bath Ankylosing Spondylitis Functional Index; CRP, C-reactive protein; HLA, human leukocyte antigen; IL, interleukin; PCR, polymerasechainreaction; ReA, reactive arthritis; SpA, spondyloarthritis; TNF, tumournecrosis factor; VTEC, verocytotoxigenic Escherichia coli; uSpA, undifferentiated spondyloarthritis

Key words: spondyloarthritis, bacteriology, serology nucleic acid-based assays together with serological testing by ELISA. Although Escherichia coli derived from phylogroup A prevailed in the gut microflora of the patients and controls, differences were observed regarding the representatives of the other phylogroups with a higher prevalence of E.coli members of phylogenetic group B1 in the stool specimens of patients. Antibodies against the targeted species were detected in SpA patients and controls, and the serological profiles of the former were more diverse and complex. In conclusion, the detection of anti-bacterial antibodies combined with other specific laboratory investigations should be more extensively used to monitor SpA patients in association with their symptoms and in order to determine and administer more effective therapeutics.

\section{Introduction}

According to the Assessment ofSpondyloArthritis (SpA) International Society (ASAS) and the European League against Rheumatism $(1,2)$, SpAis a group of associated chronic systemic inflammatory immune-mediated rheumatic diseases affecting axial and peripheral joints and entheses. SpA includes different disease phenotypes: Ankylosing spondylitis (AS), reactive arthritis (ReA), arthritis/spondylitis with inflammatory bowel disease, psoriatic arthritis and undifferentiated (u) SpA $(1,2)$. Extensive progress has been achieved in the understanding of SpA pathogenesis in the last two decades, including the complex interaction between environmental, immune, genetic and epigenetic factors (3-8). Furthermore, the gut and/or urogenital microbiota, representing one of the most important environmental factors,was revealed to have a much more complex configuration than previously thought, when studied by using modern high-throughput techniques, including genomic and metagenomic approaches (9-11). Infections with pathogens including Yersinia spp., Salmonella spp., Campylobacter spp., Shigella spp. and Chlamydia trachomatis have been reported at increasing rates worldwide $(12,13)$, with a subsequent increase in the number of patients at risk 
that are prone to developing extra-intestinal complications. ReA was reported in 2-10\% of patients with enteritis. Besides usual pathogens in the enteric and/or urinary tract (14), several other infectious agents were incriminated as triggering factors in $\mathrm{SpA}$ in a smaller percentage, including certain anaerobes (Porphyromonasgingivalis, Prevotellaintermedia) (15), Borrelia spp. (16), human immunodeficiency virus (17) and hepatitis C virus (18). Despite of remarkable scientific progress, the pathogenesis of SpAhas remained to be fully elucidated. It was demonstrated that genetic factors, including human leukocyte antigen (HLA) B27 (19-22), certain phenotypes of endoplasmic reticulum aminopeptidase-1 $(19,21,22)$, interleukin (IL)-23 receptor $(21,23)$ and tumour necrosis factor (TNF) gene polymorphisms (24) have an important role in the development of the disease and/or in persistence of bacterial components at different anatomic sites of the host. The persistence of bacterial antigens of Salmonella, Yersinia and Chlamydia trachomatis, including the presence of bacterial endotoxin and/or DNA in synovial fluid, was identified in patients with ReA (25). Differences in the serumantibody pattern amongst patients may suggest differences between triggering factors and various clinical forms of $\operatorname{SpA}(26,27)$. The aim of the present study was to improve the laboratory-based information in order to better understand the correlation between the disease activity/severity and the microbiological results/immune status against intestinal and/or urogenital pathogens.

\section{Materials and methods}

Subjects and study design. A total of 27 subjects aged 34-68 years (24 males and 3 females) diagnosed with SpA according to the ASAS criteria $(1,2)$, who had been consecutively admitted to Sf. Maria Clinical Hospital Department of Internal Medicine and Rheumatology (Bucharest, Romania) between January 2016 and December 2017, were included in the present study. Of these, 24 males and one female displayed the human leukocyte antigen (HLA)-B27 phenotype. During hospitalization, an assessment of the disease activity and functional impairment was performed based on the calculation of the Bath AS Disease Activity Index (BASDAI) (28), Bath AS Functional Index (BASFI) (29) and AS Disease Activity Score (ASDAS) (30). Regarding BASDAI and BASFI, a value between 4-6 was considered to indicatesuboptimal control of the disease activity and significant functional impairment, respectively. A value of $>6$ for BASDAI is requested in the Romanian protocol for initiating the biological treatment in AS. BASFI evaluation is not included in the evaluation for biological treatment initiation in Romanian patients with AS.For the ASDAS calculated using C-reactive protein (CRP), a value of 1.3-2.1 was considered to indicate low disease activity and a value $>2.1$ was considered to indicate high disease activity.

The patients were compared with a control group consisting of 26 randomly selected volunteers aged $>18$ years without any concomitant or overlapping autoimmune disease, or overt infection, and had no current treatment with any anti-microbial agents (antibiotics, antivirals or antifungals), age and sex-matched, admitted to the Sfanta Maria Clinical Hospital due to discogenic lower back pain. All subjects provided written informed consent. The study protocol was approved by the Local Ethics Committee of 'Sfanta Maria' Clinical Hospital (Bucharest, Romania; no. 1442/13.07.2018).

Laboratory approach. Microorganisms known to trigger $\mathrm{SpA}$ were sought in the various specimens collected from patients and controls using a combined approach relying on conventional culture technique and nucleic acid-based assays together with serological testing. The specimens submitted for microbiological investigation included stool (available from 25 patients and 26 controls), urine (available from 27 patients and 26 controls), synovial fluid (available from 3 patients) and serum (available from 27 patients and 26 controls) samples.

The screening of anti-thyroid antibodies anti-thyroid peroxidase (ATPO) and anti-thyroglobulin (ATG) was performed by enzyme-linked fluorescent assay using an automated benchtop immunoanalyzer VIDAS ${ }^{\circledR} 30$ and the ATPO and anti-Tg specific kits from the VIDAS ${ }^{\circledR}$ Thyroid panel (bioMérieux, Marcy l'Etoile, France; cat. no. 30461 and 30 462), according to manufacturer's protocol, as diagnostic tools for detecting polyautoimmunity.

The detection of HLA-B27 by polymerase chain reaction (PCR) and the determination of CRP biomarker by spectrophotometric assay (normal range, 0-5 mg/l) was performed in the Medas laboratories of 'Sfanta Maria' Hospital (Bucharest, Romania).

Culture and non-culture methods. Stool cultures were performed for the SpA-triggering bacteria Yersinia spp., Klebsiella spp., Shigella spp., Salmonella spp., Escherichia coli and Campylobacter spp. Selective and differential culture media used for the isolation of these Gram-negative bacilli were Citrate Lactose Electrolyte Deficient (CLED) agar, MacConkey agar, Desoxycholate Citrate Lactose Sucrose Agar and Campylobacter Agar Base with Campylobacter Selective Supplement. Selenite broth was also used as an enrichment medium for Salmonella spp. In addition, Sabouraud dextrose agar with chloramphenicol was used for isolating fungi. All abovementioned bacteriological media were provided by Oxoid ${ }^{\circledR}$ Ltd. (Basingstoke, UK).

Automated VITEK ${ }^{\circledR} 2$ technology and the VITEK ${ }^{\circledR} 2$ GN ID and YST ID cards (bioMérieux) were used for the identification of fermenting and non-fermenting Gram-negative bacilli and identification of yeast and yeast-like organisms, respectively.

Quantitative urine cultures were performed using CLED and a $0.001-\mathrm{ml}$ calibrated loop, and the results on microbial growth were expressed as colony forming units (CFU)/ml. A positive specimen was indicated by at least $10^{5} \mathrm{CFU} / \mathrm{ml}$ urine.

Total DNA was extracted directly from stool samples with the QIAamp DNA Stool Mini kit (cat. no. 51504 and 19590; Qiagen Inc., Hilden, Germany, UK). according to the manufacturer's protocol.

Commercially available PCR-based Seeplex ${ }^{\circledR}$ Diarrhea ACE Detection kit (cat. no DR6501Y and cat. no. DR6502Y; Seegene Technologies Inc., Seoul, Korea) was used to detect the presence of the intestinal pathogens according to the manufacturer's protocol. Bacterial panel 1, which was used for the identification of Salmonella spp. (S. bongori, S. enterica), Shigella spp. (S. flexneri, S. boydii, S. sonnei, and S. dysenteriae), and Campylobacter spp. (C. jejuni, C. coli), allowed for the concurrent detection of Vibrio spp. (V. cholerae, $V$. 
parahaemolyticus, $V$. vulnificus) and Clostridium difficile Toxin B. Bacterial panel 2 that was used to detect Yersinia enterocolitica and was also able to identify Clostridium perfringens, Aeromonas spp. (A. media, A.veronii, A. salmonicida, A. sobria, A. bivalvium, A. hydrophila), E. coli serotype O157:H7 and Verocytotoxin-producing E. coli (VTEC).

The urine specimens were screened for Chlamydia trachomatis using the Chlamydia trachomatis Quant Real PCR ${ }^{\mathrm{TM}}$ kit (cat. no. B1-100FRT100; Sacace Biotechnologies S.r.1, Como, Italy) and DNA template extracted from urine with the PureLink ${ }^{\mathrm{TM}}$ Genomic DNA Mini kit (cat. no. K182002, Invitrogen $^{\mathrm{TM}}$, Carlsbad, CA 92008, USA).

Broad-range 16S rRNA PCR was also performed to detect the presence of viable bacteria or bacterial DNA fragments in the available synovial fluid specimens. DNA extraction was performed with PureLink ${ }^{\mathrm{TM}}$ Genomic DNA Mini kit (cat. no. K182002; Invitrogen; Thermo Fisher Scientific, Inc.). Primers and protocolswere identical to those in a previously published study (31).

E. coli phylotyping was performed using the revised multiplex PCR-based protocol of Clermont et al (32), using a T100 ${ }^{\mathrm{TM}}$ thermocycler (Bio-Rad Laboratories Inc, Hercules, CA, USA). For each subject, three or four $E$. coli colonies recovered from the stool culture were tested.

Detection of antibodies against bacteria in serum and in the synovial fluid. The presence of serum antibodies against Salmonella, Campylobacter, Yersinia and Chlamydia was investigated by ELISA using the following respective commercial kits:

IMTEC Salmonella immunoglobulin (Ig)A (cat. no. ITC40050; HUMAN Biochemica und Diagnostica GmbH, Wiesbaden, Germany) and IMTEC Salmonella IgGAM (cat. no. ITC40040; HUMAN Biochemica und Diagnostica $\mathrm{GmbH}$ ), recom Well Campylobacter IgA and IgG (cat. nos. 6205 and 6204; MikrogenDiagnostik, Neuried, Germany), Anti-Yersinia enterocolitica ELISA IgG (cat. no. EI 2173-9601 G; EuroimmunMedizinischeLabordiagnostika, Luebeck, Germany), anti-Chlamydia trachomatis ELISA (IgM) and anti-Chlamydia trachomatis ELISA (IgG) kits (EI 2191 A/G/M; EuroimmunMedizinischeLabordiagnostika). In addition, serum antibodies against Klebsiella pneumoniae were detected using the classical method of tube agglutination following an in-house protocol (33). In brief, K. pneumoniae whole cells from 3 serotypes frequently involved in triggering SpA (K36, K50, K21) were used as bacterial antigens. Serum dilutions of 1:80, 1:160 and 1:320 in physiological saline solution were mixed with bacterial suspension equivalent to a 2 McFarland standard. A titer of $\geq 160$ was considered to be indicative of a positive result.

Of note, the presence of anti-Yersinia antibodies was determined in the limited number of patients that were able to be assessed repeatedly in order to investigate the dynamics of these specific antibodies in serum in correlation with their presence in the synovial fluid.

Statistical analysis. Continuous variables were reported asthe mean \pm standard deviation (interquartile range) for age and
CRP and as the median (minimum-maximum) for disease duration. Dichotomous nominal variables are reported as 'absolute frequency (percentage of subgroup total)'. Non-parametric tests ( $\chi^{2}$ and Fisher's exact tests) were used to evaluate the differences in test positivity between SpA patients and controls and the Mann-Whitney $\mathrm{U}$ test was performed to evaluate differences in age between these study groups. $\mathrm{P}<0.05$ was considered to indicate statistical significance. SPSS v.20 for Windows (IBM Corp., Armonk, NY, USA) was used for all statistical analyses.

\section{Results}

Demographic data and clinicopathological data. Demographic parameters (age, gender) and the presence of HLA-B27 antigen in patients and controls, as well as disease duration, CRP values and DAS in SpA patients are listed in Table I. Of the 27 patients with SpA (24 male and 3 female), 24 (88.9\%) were HLA-B27-positive.

Bacterial stool culture. With one exception, the stool specimens recovered from the patients with SpAwere culture-negative for the traditional intestinal pathogens, including Shigella spp., Salmonella spp., Yersinia spp. and Campylobacter spp. The only stool sample identified to be positive contained Salmonella enterica serovarRissen. As expected, E. coli was the predominant aerobic species of enterobacteria isolated from stools in the two study groups. Specifically, a virtually pure culture of $E$ coli was yielded from 23 of the patients (88\%) and 25 of the controls (96\%). The remaining 4 patients displayed stool cultures dominated by $K$. pneumoniae ( 3 patients) or Citrobacter spp. (1 patient), whereas within the control group, one subject was positive for Citrobacter spp.

DNA-based stool analysis. Phylotyping revealed that the Escherichia coli strains isolated from the available stool specimens belonged to multiple phylogroups. However, the major proportion of the strains colonizing the gut of the patients and controls belonged to phylogenetic group A. Most subjects (17 patients and 19 controls) were colonized by E. coli strains representative of only one phylogenetic group, which was mainly A, but the concomitant presence of two phylogroups was also observed. While phylogroup A prevailed in the intestinal microflora of the patients and the controls, differences were observed regarding the prevalence of the other phylogroups (Table II). Of note, phylogroup B1 and C strains were isolated exclusively from the patients.

The multiplex PCR-based panels were used as an alternative to cultureexperiments and confirmed the stool specimens that tested positive in the cultures for Salmonella. In addition, they identified patients with stool specimens positive for Clostridium perfringens $(\mathrm{n}=6)$, Clostridium difficile toxin $\mathrm{B}$ $(\mathrm{n}=1)$, Aeromonas spp. $(\mathrm{n}=1)$ and non-O157:H7 VTEC $(\mathrm{n}=2)$. The concurrent presence of Clostridium difficile toxin $\mathrm{B}$ and Aeromonas spp. was also identified in one of the SpA patients. Of note, the patient with the Citrobacter spp.-dominant culture was also identifiedto be positive for VTEC and Clostridium perfringens by PCR. In addition, 2 patients tested positive for Clostridium perfringens. Regarding the control group, PCR identified VTEC in 4 subjects, Salmonella spp.in 2, 
Table I. Clinico-pathological characteristics of the control and SpA groups.

\begin{tabular}{lccc}
\hline Paramete & $\operatorname{SpA}(\mathrm{n}=27)$ & Controls $(\mathrm{n}=26)$ & P-value \\
\hline Age (years) & $46.07 \pm 14.37(34-68)$ & $60.9 \pm 7.69(54-77)$ & $12(46.2)$ \\
Male sex & $24(88.9)$ & $2(7.7)$ & $<.001^{\mathrm{a}}$ \\
HLA-B27 & $24(88.9)$ & - & $-0.002^{\mathrm{b}}$ \\
Disease duration (years) & $5.77 \pm 6.58(1-33)$ & - & - \\
CRP (mg/l) & $12.52 \pm 10.24(1.8-32)$ & - & - \\
BASDAI & $3.35 \pm 1.7(1.1-7.0)$ & - & - \\
BASFI & $3.3 \pm 1.96(1.0-7.2)$ & - & - \\
ASDAS & $2.18 \pm 1.27(0.9-5.2)$ & & - \\
\hline
\end{tabular}

aP-value determined by the Mann-Whitney U-test or ${ }^{b} \chi^{2}$ test. The upper limit of normal for CRP is $5 \mathrm{mg} / \mathrm{l}$. Values are expressed as the mean \pm standard deviation (range) or $\mathrm{n}(\%)$. ASDAS $\mathrm{CRP}_{\mathrm{P}}$, Ankylosing Spondylitis Disease Activity Score using CRP; CRP, C-reactive protein; BASDAI, Bath Ankylosing Spondylitis Disease Activity Index; BASFI, Bath Ankylosing Spondylitis Functional Index; HLA, human leukocyte antigen; SpA, spondyloarthritis.

Table II. Escherichia coli phylogenetic groups identified in the stool samples from the two groups by using the Clermont revised multiplex polymerase chain reaction-based protocol.

\begin{tabular}{lcc}
\hline Phylogroup & $\begin{array}{r}\text { SpA patients } \\
(\mathrm{n}=25)\end{array}$ & $\begin{array}{c}\text { Controls } \\
(\mathrm{n}=26)\end{array}$ \\
\hline A & 12 & 15 \\
$\mathrm{~B} 1$ & 1 & 0 \\
$\mathrm{~B} 2$ & 2 & 0 \\
$\mathrm{C}$ & 1 & 0 \\
$\mathrm{E}$ & 0 & 1 \\
$\mathrm{~F}$ & 1 & 3 \\
A+B1 & 4 & 0 \\
A+B2 & 0 & 2 \\
A+d & 1 & 1 \\
A+E & 1 & 2 \\
A+F & 2 & 2 \\
\hline
\end{tabular}

SpA, spondyloarthritis.

Aeromonas spp.in 1 and Clostridium difficile toxin B in 1 subject, respectively (some subjects tested positive for multiple strains).

Urine analysis. The urine samples were negative for enterobacteria, enterococci and staphylococci in most patients and controls. Only 2 urine specimens from the SpA patients were culture-positive. Specifically, one specimen yielded Escherichia coli belonging to the phylogenetic group B2 and another one contained Pseudomonas aeruginosa. Among the control group, one subject was identified with a significant bacteriuria with Escherichia coli of phylogenetic group B2. Of note, the SpA patient and the control subject carried the same phylogenetic group of Escherichia coli in the stool. Chlamydia trachomatis DNA in the urine ofneither in the patients nor the controlswas identified by usingthe real-time PCR method.
Synovial fluid analysis. The synovial fluid specimens recovered from $3 \mathrm{SpA}$ patients were negative on culture and $16 \mathrm{~S}$ ribosomal RNA PCR analysis.

Serum analysis. Antibodies against bacteria were detected in $22(81 \%)$ of the SpA patients, with one exception with regard to the HLA-B27 phenotype. The prevalence of anti-bacterial antibodies detected in serum was highest for anti-Yersinia antibodies (16 patients, 67\%) followed by anti-Klebsiella antibodies (11 patients, 46\%), anti-Salmonella antibodies (5 patients, 21\%), anti-Campylobacter antibodies (5 patients, $21 \%$ ) and anti-Chlamydia antibodies (4 patients, 17\%; Table III).

Antibodies against bacteria were identified in a similar number of subjects from the control groups. Specifically, 21 controls $(81 \%)$ developed anti-bacterial antibodies, of which 12 developed antibodies against only one species (e.g. Yersinia, Klebsiella, Salmonella) and 9 against multiple species. The prevalence of the anti-bacterial antibodies detected was highest for anti-Klebsiella antibodies (14 controls, 54\%) followed by anti-Yersinia antibodies (11 controls, 42\%), anti-Salmonella antibodies (3 controls, 12\%), anti-Chlamydia antibodies ( 2 controls, $8 \%$ ) and anti-Campylobacter antibodies (1 control, 4\%; Table III).

According to the co-occurrence of antibodies against different species, an increased number of serological profiles were identified, which comprised between 1 and 4 categories of antibodies according to their bacterial trigger (Table IV). A total of 12 serological profiles were identified among the patients and 5 serological profiles within the controls, respectively. More than half of the subjects of the control group (14/26 subjects) tested positive for antibodies directed against one species of enterobacteria (i.e. Klebsiella, Yersinia or Salmonella) and most of them (19/26 subjects) had antibodies against no more than two categories of microbes. By contrast, less than one third of the SpA patients (8/27 subjects) had developed antibodies against only one species of enterobacteria, namely Yersinia or Klebsiella, while the remaining ones displayed a diversity of serological profiles with antibodies against up to four categories of microbes. 
Table III. Distribution by bacterial trigger specificity and class of Ig of anti-microbial antibodies detected in sera of SpA patients and control subjects.

\begin{tabular}{lcc}
\hline Target pathogen/antibody type & SpA group $(\mathrm{n}=27)$ & Controls $(\mathrm{n}=26)$ \\
\hline Klebsiella & $11(40.7)$ & $21(80.8)$ \\
Anti-K21 & $4(11.1)$ & $14(80.8)$ \\
Anti-K36 & $1(3.7)$ & 0 \\
Anti-K50 & $6(22.2)$ & 0 \\
Yersinia & $22(81.5)$ & $11(42.3)$ \\
IgA & $15(55.6)$ & $5(19.2)$ \\
IgG & $7(25.9)$ & $6(23.1)$ \\
Salmonella & $8(29.6)$ & $5(19.2)$ \\
IgA & $5(18.5)$ & $3(11.5)$ \\
IgG & $3(11.1)$ & $2(7.7)$ \\
Campylobacter & $7(25.9)$ & $1(3.9)$ \\
IgA & $4(14.8)$ & $1(3.9)$ \\
IgG & $3(11.1)$ & $0(0.0)$ \\
Chlamydia & $5(18.5)$ & $2(7.7)$ \\
IgA & $2(7.4)$ & $1(3.9)$ \\
IgG & $3(11.1)$ & $1(3.9)$ \\
\hline
\end{tabular}

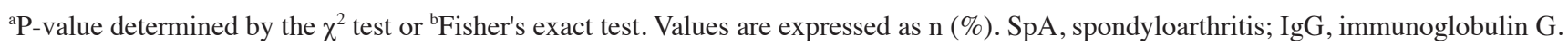

Table IV. Serological profiles ofspondyloarthritis patients and control subjects based on specific antibodies against target pathogens.

Serological profile (species specificity of antibodies) Patients Control group

\begin{tabular}{lll}
\hline K & 2 & - \\
Y, K & 3 & 3 \\
Camp, K & 1 & 0 \\
Chl, K & 1 & 0 \\
Y, Camp & 1 & 0 \\
Y, Chl & 0 & 1 \\
Y, Sal & 1 & 1 \\
Chl, Sal & 1 & 0 \\
Y, Camp, K & 1 & 0 \\
Y, Chl, K & 1 & 0 \\
Y, Sal, K & 0 & 1 \\
Y, Chl, Camp & 1 & 0 \\
Y, Camp, Chl, K & 0 & 1 \\
Y, Sal, Camp, K & 1 & 0 \\
Y, Sal, Chl, K & 1 & 0 \\
\hline
\end{tabular}

Y, Yersinia enterocolitica; Camp, Campylobacter; Chl, Chlamydia trachomatis; K, Klebsiellapneumoniae; Sal, Salmonella.

The three most complex serological profiles detected in the present study comprised a combination of anti-enterobacterial antibodies with either anti-Campylobacter or anti-Chlamydia antibodies and the profiles obtained for patients with $\mathrm{SpA}$ differed from those of the control group. They were identified in 3 patients and one control subject, respectively. Of note,with regard to anti-Yersinia antibodies, the IgA class was clearly better represented in patients than in controls.

Certainresults associated with the immunological and microbiological status are worth mentioning. For instance, of the 3 patients who were initially positive for anti-Yersinia antibodies, the 2 who displayed a HLA-B27 phenotype were re-tested for anti-Yersinia antibodies after a 6-month interval. In one patient, the antibody titer increased, in another one, the titer was unchanged and in the third patient, antibodies with new specificities were detected (i.e. anti-Klebsiella pneumoniae and anti-Campylobacter antibodies in the second serum sample) with concomitant isolation of Klebsiella pneumoniae from feces. The first case was a HLA-B27-positive patient with a disease duration of 30 years and clinical diagnosis of AS associated with uveitis. A progressive increase in anti-Yersinia $\operatorname{IgA}$ antibody titer was observed in the three sera sampled at intervals of 6 months during the study, as follows (optical density at $450 \mathrm{~nm}$ ): 0.980 (first sample), 1.103 (second sample) and 2.287 (third sample).

Anti-Salmonella antibodies were detected mostly in the serum of HLA-B27-positive patients in whom other antibodies were detected concomitantly. One of the 5 patients positive for anti-Salmonella antibodies ( $\operatorname{IgA}$ and $\operatorname{IgG}$ ), who was also positive for Yersinia and anti-Campylobacter IgA antibodies, had a concomitant extraintestinal complication (uveitis). Enterobacteria were dominant in this patient's intestinal microbiota with $E$. coli derived from phylogenetic group B2. The patient had a history of urinary tract infections. A second sampling of feces from this patientindicated dominant Klebsiella pneumoniae and E. coli phylogenetic group B2 detected in culture, but sterile urine cultures. For this patient, 
Table V. Number of spondyloarthritis patients with anti-bacterial antibody positivity/negativity according to disease activity score categories.

\begin{tabular}{|c|c|c|c|c|c|c|}
\hline \multirow[b]{2}{*}{ Antibody/status } & \multicolumn{2}{|c|}{ BASDAI } & \multicolumn{2}{|c|}{ BASFI } & \multicolumn{2}{|c|}{$\mathrm{ASDAS}_{\mathrm{CRP}}$} \\
\hline & $4-6$ & $>6$ & $4-6$ & $>6$ & $1.3-2.1$ & $>2.1$ \\
\hline \multicolumn{7}{|l|}{ IgA } \\
\hline Positive & 2 & 1 & 5 & 2 & 4 & 6 \\
\hline Negative & 1 & 1 & 1 & 1 & 0 & 2 \\
\hline \multicolumn{7}{|l|}{ IgG } \\
\hline Positive & 2 & 3 & 4 & 3 & 5 & 5 \\
\hline Negative & 1 & 1 & 2 & 2 & 1 & 3 \\
\hline
\end{tabular}

Ig, immunoglobulin; ASDAS ${ }_{\mathrm{CRP}}$, Ankylosing Spondylitis Disease Activity Score using CRP; CRP, C-reactive protein; BASDAI, Bath Ankylosing Spondylitis Disease Activity Index; BASFI, Bath Ankylosing Spondylitis Functional Index.

anti-Yersinia antibodies wereidentified in serum and synovial fluid specimens. The concomitant presence of anti-Yersinia antibodies in serum and synovial fluid was also observed for the other 2 patients who providedthe two types of specimen (serum and synovial fluid) for laboratory analysis.

Among the 16 anti-Yersiniaantibody-positive patients, only 2 were detected positive for ATPO and two for ATG antibodies. In one of these patients in whom an increase in the titer of anti-Yersinia antibodies was identified at a 1-year interval after the first sampling, the first sample was positive for ATPO and ATG and the second sample remained positive. This patient was diagnosed with SA 17 years prior to being enrolled in the present study.In the control group $(n=26) 2$ of the 11 subjects that were positive for anti-Yersinia antibodies were concomitantly positive for ATPO antibodies.

The presence of antibacterial antibodies in patients with different levels of disease activity (assessed by ASDAS $_{\mathrm{CRP}}$ BASFI and BASDAI scores) is presented in Table V. The number of subjects wasinsufficient for statistical evaluation (Table V).

\section{Discussion}

The present study aimed to investigate whether the different patterns of clinical manifestation and disease progression in $\mathrm{SpA}$ may be explained by differences in initial infectious triggering factors and whether the overall dynamics of the microbial/host association in patients impacts their genetic predisposition to developing SpA. Several previous studies demonstrated that a fraction of patients initially diagnosed with ReA further developed AS. For instance, Herrlinger and Asmussen (34) reported that 5\% of the patients with $\operatorname{ReA}$ triggered by Yersinia spp. developed AS and another $5 \%$ of patients with pre-existing AS progressed. Sairanen et al (35) reported that in patients presenting with ReA triggered by Shigella spp. 20 years earlier, 14\% had AS and 32\% had radiologically confirmed sacroiliitis. In addition, up to $20 \%$ of patients with ReA developed AS after 10-20 years, as reported by Leinsalo-Repo (36). In a 10-year observational study, Amor et al (37) reported that radiologically positive sacroiliitis was observed in $\sim 30 \%$ of patients with Reiter's disease, usually triggered by urethritis.
The clearest indication of the association between the intestinal microbiota and joint damage in SpA is the triggering of ReA following previous gastrointestinal infections with bacteria including Salmonella, Shigella, Yersinia and Campylobacter (38).

In addition, it should be noted that bacterial components from previous infections may be recovered from the joints of patients who developed ReA (39-41). Hypothetically, the detection of intestinal pathogens associated with autoimmune diseases, including Salmonella spp., Yersinia spp., Campylobacter spp., Klebsiella pneumoniae, Shigella spp. and fungi, in different biological samples including saliva, synovial fluid or feces would aid in the identification of triggering factors and assessing the evolution of the specific immune status towards these bacterial pathogens. According to previous studies, triggering microorganisms may be cultivated from feces during a variable time interval following the initial infection $(42,43)$. Serological methods including ELISA may also be useful to identify proof of previous infectious episodes in patients who tested negative by culture-based methods (43).

It is preferable to demonstrate an increasing titer of $\mathrm{IgG}$ antibodies or high persistent levels of $\operatorname{IgA}$ in patients with autoimmune diseases, given the fact that IgA usually has a shorter half-life than IgG. The presence of $\mathrm{IgG}$ autoantibodies confirms a previous contact with the corresponding bacteria (41).

Several studies have suggested that Yersinia,Salmonella and Chlamydia trachomatis are the most common ReA-triggering bacteria, and that these bacteria are also present in patients with undifferentiated arthritis (44-48). Therefore, an increase in the titer of specific bacterial antibodies is considered to be an important criterion for identifying any triggering bacteria for these autoimmune diseases. In the present study, the principal results obtained by re-assessing the microbiological and immunological status and disease activity/functional scores of the 27 patients with SpA at different time-points following the onset of disease, generally confirmed the previously described results; however, they also provided additional information that will be discussed hereinafter.

The distribution of patients of the present study by sex and the presence of HLA-B27 were similar to those in previously reported studies (19-22). Though obligate enteric pathogens 
were only identified in 1 patient with $\mathrm{SpA}$ and in none of the subjects of the control group, the present study observed slight differences regarding the presence of opportunistic Klebsiella species, which were only present in the SpA group (12.0\% of feces samples). In addition, the distribution of Escherichia coli isolates by phylogenetic groups exhibited slight differences from that reported in the previous literature, with B1 present only in the SpA group, and the E group only being present in the control group. The patients and control subjects with the B2 phylogenetic group of Escherichia coli in stool samples also exhibited the same phylogenetic group in their urine samples and reported frequently occurring symptoms, including urinary tract infections. Previous data also support the dominance and the etiological role of Klebsiella spp, which was isolated from the stool samples of patients with AS (49,50). A recent study has reported that Escherichia coli strains of phylogenetic groups B2 and D are able to produce virulence factors, which may disturb the immune response, while the phylogenetic group B2 may impede the regulatory mechanism of toll-like receptor signaling (51). A genetic molecular investigation was used in the present study for the detection of Clostridium spp. and Aeromonas spp. genes, as these bacterial genera have been implemented in the etiology of SpA (52). It should be noted that by using the PCR method, the presence of Salmonella spp. in the feces of the HLA-B27 positive patients who had been diagnosed with Salmonella reissen by traditional methods (culture) was not detected. This may be due to the presence of PCR inhibitors in the feces, or due to the inability to detect the cultivated species by the nucleotide probe used in the reaction kits. This result supports the requirement to combine classical and molecular methods for microbiological investigations in patients with SpA.

In the present study, several patients who had initially been diagnosed with ReA following an intestinal infection developed AS, whereas other patients, who had already been diagnosed with AS and who were also positive for anti-bacterial antibodies exhibited disease progression, which confirmed the results of a previously published study (37). A total of 18 of the 27 patients with $\mathrm{SpA}$ tested positive for at least 1 bacterial specific antibody, while the concomitant presence of 2 or 3 different bacterial-specific antibodies was identified in 9 out of the 27 patients. In the present study, over half of the patients $(n=16)$ were positive for Yersinia antibodies, of which 6 were positive for $\mathrm{IgG}$ and $\mathrm{IgA}$ antibodies, and 7 tested positive for other types of antibodies concomitantly. There was a marked difference between the number of Yersinia-positive antibodies between the patients and the control group.

The positivity for IgA-specific bacterial antibodies was betterreflected by the $\mathrm{ASDAS}_{\mathrm{CRP}}$ and BASFI than by the BASDAI. However, 2 of the 6 patients with SpA had highly modified inflammatory score, with one of these patients exhibiting high BASDAI (>4), BASFI (>6) and ASDAS $_{\mathrm{CRP}}$ $(>2.1)$ values. The inflammatory markers were better associated with the presence of anti-Yersinia antibodies in the 16 HLA-B27-positive patients, and 8 out of the 16 patients had CRP values $>3$ times the upper limit of normal. All HLA-B27-positive patients exhibited high BASDAI, BASFI and ASDAS $_{\mathrm{CRP}}$.

Previous studies have demonstrated that in Yersinia-induced acute $\operatorname{ReA}$, IgG antibodies associated with IgA antibodies may be detected in nearly $100 \%$ of the patients $(53-55)$. The persistence of $\operatorname{IgA}$ antibodies in the serum of patients with Yersinia-induced arthritis was observed for 14-16 months following the initial diagnosis in $84 \%$ of patients (56), and high levels of $\operatorname{IgA}$ are directly correlated with the severity of the disease $(56,57)$. In patients without arthritic symptoms, these antibodies disappeared within 5 months. In addition, anti-Yersinia IgG antibodies were more persistent in arthritic patients when compared with non-arthritic patients; however, not as consistently as $\operatorname{Ig} \mathrm{A}$ antibodies (56). This previous study also demonstrated that IgM antibodies persist for only 1-3 months following the onset of infection (54), and these antibody levels persisted for longer among patients with ReA (9-14 months) and patients with undifferentiated arthritis, when compared with those with uncomplicated enterocolitis (4 months) (58). In salmonellosis, all classes of IgA, IgG and IgM antibodies were observed to persist, unlike Yersinia-triggered ReA, where only $\operatorname{IgA}$ antibodies persisted, particularly in the IgA2 subclass (59).

Campylobacter species are able to induce gastrointestinal and systemic diseases in humans, and have not only been associated with acute disease, but also with a wide range of chronic inflammatory diseases (60). Patients with SpA may have IgG anti-Campylobacter antibodies in the same range as those of healthy subjects, and this may be due to poultry consumption in the general population (41). In the present study, 4 out of 5 patients who tested positive for anti-Campylobacter antibodies were also positive for other bacterial antibodies detected in the serum. However, no strains of Campylobacterspp. were detected in the analyzed feces.

High levels of Salmonella antibodies towards several Salmonella antigens have been reported previously $(46,61)$. A study by Durán-Avelar et al (62) revealed that $71.4 \%$ of Salmonella IgG and IgA antibody-positive AS patients and $14.3 \%$ of control subjects, the proteic $30-\mathrm{kDa}$ band of Salmonella typhimurium was recognized by using human anti-IgG western blot analysis. However, not all Salmonella species are associated with SpA. In addition to the previously mentioned p30 antigen of Salmonella typhimurium (63), it has been reported that the Salmonella typhi heat shock protein 60 antigen is also involved in the pathogenesis of SA (64). However, the association between the observed antibody levels and the mechanisms involved in the pathogenesis of AS have remained to be completely elucidated. In the sera from patients with SpA and healthy controls, all $4 \mathrm{IgG}$ subclasses were revealed to be involved in p30 recognition of Salmonella typhimurium, while only the $\mathrm{IgG} 3$ antibody response to p30 was significantly different in patients with AS when compared with healthy subjects (63). The involvement of outer membrane protein $\mathrm{H}$ of Salmonella spp. in SpA pathogenesis was not supported by the presence of antibodies or the cellular immune response to this peptide (65). The association of Salmonella spp. with SpA is also supported by the presence of Salmonella spp. antigens in the synovial fluid of patients with SpA (66). However, the behavior of Salmonella typhimurium is influenced by the presence of HLA-B27 in transfected cells, leading to the increased production of interleukin (IL)-6, IL-8 and IL-10, and the attenuated production of TNF- $\alpha$ (67-69).

Previous studies have suggested that mucous membranes and their immune systems serve a pathological role in the 
development and maintenance of numerous auto-inflammatory diseases, including SpA (70-72). Salas-Cuestas et al (71) reported that there was a higher mean $\mathrm{SgA}$ concentration in patients with ReA and uSpA, independent of the HLA-B27 allele and disease duration. In the study of Granfors and Toivanen (72), there was a significant difference in the serum levels of SIgA, particularly anti-Yersinia enterocolitis in patients who developed arthritis following a confirmed infection. In the present study, the percentage of subjects with anti-Salmonella antibodies detected in serum did not differ between the controls and patient groups. This may be explained either by contact with Salmonella from food sources or by the fact that several subjects from the control group were laboratory workers who were repeatedly exposed to enteric pathogens.

The study of Salas-Cuestas et al (71) identified the presence of serum IgA anti-Chlamydia trachomatis antibodies levels higher than the reference value in $20 \%$ of patients with SpA. Conversely, none of the subjects in the control group had elevated levels of anti-Chlamydia trachomatis antibodies in serum SIgA or IgA. The same authors observed anassociation between serum inflammatory markers, including high CRP, and the serum levels of SIgA in uSpA and ReA (71). In 1996, Wendling et al (73) reported similar results regardingSIgA and CRP in patients with AS. A moderate correlation between the clinical indices of disease activity, i.e. BASDAI and $\mathrm{ASDAS}_{\mathrm{CRP}}$, and the serum concentration of SIgA was demonstrated. These positive correlations were stronger in the HLA-B27-positive subgroup and in patients with symptoms that had persisted for over 12 months. In addition, the strongest association was in the HLA-B27-positive subgroup. The abovementioned authors demonstrated that an increase in the serum concentration of SIgA translates into a better clinical control of the disease, arguing that the serum concentration of SIgA modulates the clinical status of patients with ReA and uSpA. A longer monitoring period would provide sufficient evidence to determine whether a high and persistent level of total $\operatorname{Ig} \mathrm{A}$ is able to modulate the progression of the disease to structural sacroiliac involvement or the development of extensive axial inflammation, as suggested by Franssen et al (74). The study by Cowling et al (75) confirmed the conclusions of several previous studies, demonstrating that serum $\operatorname{IgA}$ is increased in AS, and they reported that these high IgA values are predominantly associated with AS active phases, which were indicated by high CRP values. In the present study, 3 patients were detected to have Chlamydia trachomatis antibodies (IgA), 4 out of 5 patients were HLA-B27 positive, and these patients also exhibited other antibody types, had a high presence of inflammatory markers and a high BASFI score. Patients who tested positive for IgG anti-Chlamydia trachomatis antibodies were HLA-B27-positive and had high inflammatory markers with a CRP > 3 times the upper limit of normal, high disease scores, including BASDAI, BASFI and ASDAS, and ocular manifestations; however, these patients were only positive for the IgG class of antibodies. In the healthy control group, 1 out of 26 subjects harbored anti-Chlamydia trachomatis antibodies, i.e. IgA and IgG. In addition, Chlamydia trachomatis was not detected in the urine of subjects from the patient or the control groups by genetic methods.

Different immunological studies performed by independent groups from 16 different countries revealed that antibodies against Klebsiella pneumoniae, but not against any other microorganisms, are significantly elevated among patients with SpA compared with those in patients with other diseases (hospital outpatients with fractures) or with healthy controls (76-80); however, these results have not been confirmed by any other studies. Smith et al (81) identified no correlation between the presence of Klebsiella in the fecal flora of patients with primary AS or in association with inflammatory bowel disease, ReA or psoriatic arthritis, and disease activity, CRP or ESR. In addition, the levels of Klebsiella antibodies were identified to be significantly higher in serum than in synovial fluid samples taken from patients with AS (82). The differences between these results may be explained by the differences between the collection and culture methods for feces and the disease status at the time-point of sampling. Furthermore, a Finnish study reported that high levels of anti-Klebsiella IgA antibodies in patients with AS were correlated with the degree of intestinal inflammation (80). It is well documented that there is a strong link between intestinal inflammation and AS (83), and an increased concentration of Klebsiella pneumoniae isolated from the feces of patients with AS with peripheral arthritis and ocular disease has been demonstrated previously (73). In addition, there is evidence of high levels of IgA against Klebsiella antigens in patients with active AS $(53,83)$. The results of these studies linking Klebsiella, collagen and HLA-B27 to AS may explain various predominant clinical, genetic and immunological features present in patients with this disease (76). In the present study, paradoxically, the controls had a significantly higher prevalence of anti-Klebsiella antibodies than the patients with $\mathrm{SpA}$. Of the $10 \mathrm{SpA}$ patients positive for anti-Klebsiella pneumoniae antibodies, a high presence of inflammatory markers was identified in 4 patients, and the high BASDAI and BASFI values were correlated with the presence of inflammatory markers. In a 33-year-old patient from the present study, cultures dominated by Klebsiella pneumoniae were detected in the second sample of feces.

In the present study, 6 patients, being HLA-B27-positive, had concomitant ocular complications, and it was noted that in 3 of these patients, a Klebsiella pneumonia-dominant culture was isolated from feces. The ASDAS $_{\mathrm{CRP}}$ was $>2.1$, which is indicative of intestinal inflammation. Inflammation of the bowel may be a source of contamination and responsible for the transportation of bacterial components to various sterile sites in the body, including the joints and eyes. In the present study, the concomitant presence of 2 or 3 types of antibodies were detected in 3 out of 6 uveitis patients.

The involvement of bacterial antigens, particularly Yersinia spp., in thyroid autoimmunity was hypothesized as early as the 1970s. In 1976, Shenkman and Bottone (84) reported titers of $>1: 8$ in $75 \%$ of 67 patients in the USAdiagnosed with a variety of thyroid disorders, in contrast with the low prevalence of antibodies in controls $(>8 \%)$. The most prevalent antibodies developed against serotype 3 occurred in the highest titers, and were commonly identified in patients with Graves' disease (84).

An Italian study published in 2017, which aimed to assess the molecular mimicry theory in autoimmune thyroid disease hypothesized 40 years ago, revealed that 'in genetically pre-disposed persons and under particular conditions, molecular mimicry between microbial and human antigens can 
turn a defensive immune response into autoimmunity' (85). The authors also performed an in silico search for amino acid sequence homologies between several microbial antigens and thyroid autoantigens. These Bioinformatics-based results support the overlap between bacterial protein antigens and known autoepitopes, and the occurrence of specific HLA-DR binding motifs, and may explain the previously suggested triggering role of Borrelia, Yersinia, Clostridium botulinum, Rickettsia prowazekii and Helicobacter pylori. New data provided by the abovementioned study suggests the potential pathogenic importance of Toxoplasma gondii, certain Bifidobacteria and Lactobacilli, Candida albicans, Treponema pallidum and the hepatitis $\mathrm{C}$ virus in autoimmune thyroid disease (82).

However, a Danish study performed in 2006, investigating whether a correlation exists between the presence of Yersinia-specific antibodies and thyroid antibodies in a twin population, advanced the opinion that 'Yersinia infection does not confer an increased risk of thyroid antibodies and the genetic contribution in the acquisition of Yersinia infection is modest' (86).

On the other hand, in a comprehensive $\mathrm{PhD}$ thesis defended in 2008 by Strieder (87) entitled 'The Amsterdam autoimmune thyroid disease cohort' demonstrated that despite the fact that genetic factors exert pivotal functions in the pathogenesis of autoimmune thyroid diseases, environmental risk factors, including low birth weight, iodine excess and deficiency, selenium deficiency, parity, oral contraceptive use, reproductive span, fetal microchimerism, stress, seasonal variation, allergy, smoking, radiation damage to the thyroid gland as well as viral and bacterial infections all serve pivotal roles in the development of autoimmune thyroid disorders.

In the present study, only 2 of the 16 anti-Yersinia antibody-positive patients were detected to be positive for ATPO and 2 for ATG antibodies. Of note, 2 of the patients in the control group who had anti-Yersinia antibodies also tested positive for ATPO antibodies.

A very complex approach was promoted in 2017 by Bliddal et al (88), who advanced the concept of 'polyautoimmunity', culminating in the hypothesis of a 'generalized dysregulation of immune system'. They concluded that the complex mechanism may be described by a 'Swiss cheese model', involving coincident immunity holes made from specific HLA, immunoregulatory and thyroid-specific genes, as well as environmental and existential factors, which may contribute to autoimmunity (88). This novel concept may be useful for clinical practitioners with respect to reconsidering the significance of the concomitant presence of thyroid autoantibodies in SA and taking into consideration therapeutic schedules addressing the underlying immune dysregulation in the context of polyautoimmunity.

In the present study, the most notable data provided by the complex bacteriological phenotypic/genotypic and serological investigation indicated that, compared with the controls, patients with SpA had a markedly higher prevalence of phylogenetic group B1 Escherichia coli in stool cultures (16.0 vs. $0 \%$ ), a higher prevalence of anti-Yersinia antibodies in the serum (81.5 vs. $42.3 \%)$ and a higher prevalence of anti-Campylobacter antibodies in the serum (25.9 vs.3.9\%). IgA anti-Yersinia antibodies were significantly better represented in patients with SpA than in control subjects. In addition, there were more patients positive for anti-bacterial serum antibodies in the upper categories of SpA disease activity when compared with the group with inactive disease. In certain patients with SpA with high clinical scores, thyroid-specific autoantibodies were also identified.

The difference in age and gender composition betweenthe two groups of the present study (SpA and controls) is unlikely to have significantly influenced any of the factors investigated, since a previous studyindicated that important changes in the gut microbiota occur in subjects aged $<20$ and $>70$ years (elderly type) (86).

In conclusion, $\mathrm{SpA}$ are systemic inflammatory diseases with complex pathogeny. Intestinal microbiota alteration (in conjunction with genetic predisposition and abnormal immune activation) is one of the mechanisms proposed for the initiation and development of SpA. The detection of anti-bacterial antibodies combined with other complex specific laboratory investigations may provide valuable information for better diagnosis, monitoring of the disease activity or for the prediction of disease progression and treatment in SpA and should be used more extensively to monitor patients with $\mathrm{SpA}$ in association with their symptoms and treatment options. Further data are required in order to propose modification of the current laboratory evaluation and standard of care.

\section{Acknowledgements}

Not applicable.

\section{Funding}

The present study was supported with funds awarded by the Romanian National Agency for Research and Innovation (project code NUCLEU PN 16390104 coordinated by DC).

\section{Availability of data and materials}

The datasets used and/or analysed during the present study are available from the corresponding author on reasonable request.

\section{Authors' contributions}

ASC, MMA, AP were responsible for microbiological experiments, including phenotyping and antibacterial antibody detection. BEL was responsible for molecular detection of intestinal pathogens. CMC was responsible for molecular typing of Escherichia coli strains. AMN performed anti-ATPO, anti-ATG and antibacterial antibody detection. AIC performed molecular detection of Chlamydia trachomatis in urine. IC was responsible for study design and writing of the article. DC was responsible for study design, phenotypic and molecular detection/identification of bacterial pathogens, antibacterial antibody detection and writing of the article. MIP, provided scientific advice and performed a critical review of the manuscript. VCB was responsible for the recruitment of patients, clinical and biological evaluation of the disease, blood, urine, synovial fluid and stool sampling, and the final revision of the manuscript. DP and RI were responsible for the recruitment of patients and clinical evaluation of the disease. 
MT was responsible for the recruitment of patients, clinical and biological evaluation of the disease, and blood, urine, synovial fluid and stool sampling. CP performed the statistical analysis. DAS provided scientific advice and critical reviewed the manuscript.

\section{Ethical approval and consent to participate}

All subjects provided written informed consent. The study protocol was approved by the Local Ethics Committee of 'Sfanta Maria' Clinical Hospital (Bucharest, Romania; no. 1442/13.07.2018).

\section{Patient consent for publication}

Not applicable.

\section{Competing interests}

The authors declare that they have no competing interests.

\section{References}

1. Rudwaleit M, van der Heijde D, Landewé R, Listing J, Akkoc N, Brandt J, Braun J, Chou CT, Collantes-Estevez E, Dougados M, et al: The development of Assessment of SpondyloArthritis international Society classification criteria for axial spondyloarthritis (part II): Validation and final selection. Ann Rheum Dis 68: 777-783, 2009.

2. Rudwaleit M, Landewé R, van der Heijde D, Listing J, Brandt J, Braun J, Burgos-Vargas R, Collantes-Estevez E, Davis J, Dijkmans B, et al: The development of Assessment of SpondyloArthritis international Society classification criteria for axial spondyloarthritis (part I): Classification of paper patients by expert opinion including uncertainty appraisal. Ann Rheum Dis 68: 770-776, 2009.

3. Reveille JD and Arnett FC: Spondyloarthritis: Update on pathogenesis and management. Am J Med 118: 592-603, 2005.

4. Ambarus C, Yeremenko N, Tak PP and Baeten D: Pathogenesis of spondyloarthritis: Autoimmune or autoinflammatory? Curr Opin Rheumatol 24: 351-358, 2012.

5. Long S, Ma L, Wang D and Shang X: High frequency of circulating follicular helper $\mathrm{T}$ cells is correlated with B cell subtypes in patients with ankylosing spondylitis. Exp Ther Med 15: 4578-4586, 2008.

6. Xu Z, Wang X and Zheng Y: Screening for key genes and transcription factors in ankylosing spondylitis by RNA-Seq. Exp Ther Med 15: 1394-1402, 2018.

7. Wang C, Liao Q, Hu Y and Zhong D: T lymphocyte subset imbalances in patients contribute to ankylosing spondylitis. Exp Ther Med 9: 250-256, 2015.

8. Zervou MI, Dimopoulou DG, Eliopoulos E, Trachana M, Pratsidou-Gkertsi P, Andreou A, Sidiropoulos P, Spandidos DA, Garyfallos A and Goulielmos GN: The genetics of juvenile idiopathic arthritis: Searching for new susceptibility loci. Mol Med Rep 16: 8793-8798, 2017.

9. Manasson J, Shen N, Garcia Ferrer HR, Ubeda C, Iraheta I, Heguy A, Von Feldt JM, Espinoza LR, Garcia Kutzbach A, Segal LN, et al: Gut microbiota perturbations in reactive arthritis and postinfectious spondyloarthritis. Arthritis Rheumatol 70: 242-254, 2018.

10. Kabeerdoss J, Sandhya P and Danda D: Gut inflammation and microbiome in spondyloarthritis. Rheumatol Int 36: 457-468, 2016.

11. Schaeverbeke T, Truchetet ME and Richez C: Gut metagenome and spondyloarthritis. Joint Bone Spine 80: 349-352, 2013.

12. Schmitt SK: Reactive Arthritis. Infect Dis Clin North Am 31: 265-277, 2017

13. Tuuminen T, Lounamo $\mathrm{K}$ and Leirisalo-Repo M: A review of serological tests to assist diagnosis of reactive arthritis: Critical appraisal on methodologies. Front Immunol 4: 418, 2013.

14. Girschick HJ, Guilherme L, Inman RD, Latsch K, Rihl M, Sherer Y, Shoenfeld Y, Zeidler H, Arienti S and Doria A: Bacterial triggers and autoimmune rheumatic diseases. Clin Exp Rheumatol 26: S12-S17, 2008
15. Öğrendik M: Oral anaerobic bacteria in the etiology of ankylosing spondylitis. Clin Med Insights Arthritis Musculoskelet Disord 10: 1179544117712992, 2017.

16. Arvikar SL, Crowley JT, Sulka KB and Steere AC: Autoimmune arthritides, rheumatoid arthritis, psoriatic arthritis, or peripheral spondyloarthritis following lyme disease. Arthritis Rheumatol 69: 194-202, 2017.

17. Lebrun D, Hentzien M, Cuzin L, Rey D, Joly V, Cotte L, Allavena C, Dellamonica P, Servettaz A and Bani-Sadr F; the Dat'AIDS study group: Epidemiology of autoimmune and inflammatory diseases in a French nationwide HIV cohort. AIDS 31: 2159-2166, 2017.

18. Becker J and Winthrop KL: Update on rheumatic manifestations of infectious diseases. Curr Opin Rheumatol 22: 72-77, 2010.

19. Vitulano C, Tedeschi V, Paladini F, Sorrentino R and Fiorillo MT: The interplay between HLA-B27 and ERAP1/ERAP2 aminopeptidases: From anti-viral protection to spondyloarthritis. Clin Exp Immunol 190: 281-290, 2017.

20. Popa OM, Bojinca M, Bojinca V, Ciofu C, Dutescu MI, Bardan A, Sfrent-Cornateanu R, Petrek M, Bara C and Popa L: Distribution of HLA-B27 in Romanian spondyloarthritides patients. Int J Immunogenet 37: 513-516, 2010.

21. Colbert RA, DeLay ML, Klenk EI and Layh-Schmitt G: From HLA-B27 to spondyloarthritis: A journey through the ER. Immunol Rev 233: 181-202, 2010.

22. Cherciu M, Popa LO, Bojinca M, Dutescu MI, Bojinca V, Bara C and Popa OM: Functional variants of ERAP1 gene are associated with HLA-B27 positive spondyloarthritis. Tissue Antigens 82: 192-196, 2013.

23. Popa OM, Kriegova E, Popa L, Schneiderova P, Dutescu MI, Bojinca M, Bara C and Petrek M: Association study in Romanians confirms IL23A gene haplotype block rs2066808/rs11171806 as conferring risk to psoriatic arthritis. Cytokine 63: 67-73, 2013.

24. Popa OM, Bojinca M, Bojinca V, Dutescu MI, Meirosu M, Caisan RE, Ciofu C, Bara C and Popa LO: A pilot study of the association of tumor necrosis factor alpha polymorphisms with psoriatic arthritis in the Romanian population. Int J Mol Sci 12: 5052-5059, 2011.

25. Astrauskiene D and Bernotiene E: New insights into bacterial persistence in reactive arthritis. Clin Exp Rheumatol 25: 470-479, 2007.

26. Newkirk MM: Antibacterial antibodies and arthritis: Is there a link? J Clin Rheumatol 12: 1-2, 2006.

27. Clermont O, Bonacorsi S and Bingen E: Rapid and simple determination of the Escherichia coli phylogenetic group. Appl Environ Microbiol 66: 4555-4558, 2000.

28. Garrett S, Jenkinson T, Kennedy LG, Whitelock H, Gaisford P and Calin A: A new approach to defining disease status in ankylosing spondylitis: The Bath Ankylosing Spondylitis Disease Activity Index. J Rheumatol 21: 2286-2291, 1994.

29. Calin A, Garrett S, Whitelock H, Kennedy LG, O'Hea J, Mallorie P and Jenkinson T: A new approach to defining functional ability in ankylosing spondylitis: The development of the Bath Ankylosing Spondylitis Functional Index. J Rheumatol 21: 2281-2285, 1994.

30. Lukas C, Landewé R, Sieper J, Dougados M, Davis J, Braun J, van der Linden $\mathrm{S}$ and van der Heijde D; Assessment of SpondyloArthritis international Society: Development of an ASAS-endorsed disease activity score (ASDAS) in patients with ankylosing spondylitis. Ann Rheum Dis 68: 18-24, 2009.

31. Wilbrink B, van der Heijden IM, Schouls LM, van Embden JD, Hazes JM, Breedveld FC and Tak PP: Detection of bacterial DNA in joint samples from patients with undifferentiated arthritis and reactive arthritis, using polymerase chain reaction with universal 16S ribosomal RNA primers. Arthritis Rheum 41: 535-543, 1998.

32. Clermont O, Christenson JK, Denamur E and Gordon DM: The Clermont Escherichia coli phylo-typing method revisited: Improvement of specificity and detection of new phylo-groups. Environ Microbiol Rep 5: 58-65, 2013.

33. Santos A, de Andrade Luz L, Napoleão TH, Paiva PMG and Coelho LCBB: Coaggulation, flocculation, agglutination and hemagglutination: Similar properties? Adv Chem Res 20: 51-70, 2014

34. Herrlinger JD and Asmussen JU: Long term prognosis in yersinia arthritis: Clinical and serological findings. Ann Rheum Dis 51: 1332-1334, 1992.

35. Sairanen E, Paronen I and Mähönen H: Reiter's syndrome: A follow-up study. Acta Med Scand 185: 57-63, 1969.

36. Leirisalo-Repo M: Prognosis, course of disease, and treatment of the spondyloarthropathies. Rheum Dis Clin North Am 24: 737-751, 1998 . 
37. Amor B: Reiter's syndrome: Long-term follow-up data. Ann Rheum Dis (38 Suppl 1): Suppl S32-S33, 1979.

38. Ebringer A and Wilson C: HLA molecules, bacteria and autoimmunity. J Med Microbiol 49: 305-311, 2011.

39. Asquith M, Elewaut D, Lin P and Rosenbaum JT: The role of the gut and microbes in the pathogenesis of spondyloarthritis. Best Pract Res Clin Rheumatol 28: 687-702, 2014.

40. Asquith M and Rosenbaum JT: The interaction between host genetics and the microbiome in the pathogenesis of spondyloarthropathies. Curr Opin Rheumatol 28: 405-412, 2016.

41. Hill Gaston JS and Lillicrap MS: Arthritis associated with enteric infection. Best Pract Res Clin Rheumatol 17: 219-239, 2003.

42. Hughes RA and Keat AC: Reiter's syndrome and reactive arthritis: A current view. Semin Arthritis Rheum 24: 190-210, 1994.

43. Wollenhaupt J, Hartmann F, Köhler L, Kuipers JG, Nettelnbreker E, Frosch M and Zeidler H: Evaluation of ELISA to detect Chlamydia trachomatis antigen in urine samples from arthritis patients. Clin Exp Rheumatol 15: 169-174, 1997.

44. Fendler C, Laitko S, Sorensen H, Gripenberg-Lerche C, Groh A, Uksila J, Granfors K, Braun J and Sieper J: Frequency of triggering bacteria in patients with reactive arthritis and undifferentiated oligoarthritis and the relative importance of the tests used for diagnosis. Ann Rheum Dis 60: 337-343, 2001.

45. Honda K, Iwanaga N, Izumi Y, Tsuji Y, Kawahara C, Michitsuji T, Higashi S, Kawakami A and Migita K: Reactive arthritis caused by yersinia enterocolitica enteritis. Intern Med 56: 1239-1242, 2017.

46. Rohekar S, Tsui FW, Tsui HW, Xi N, Riarh R, Bilotta R and Inman RD: Symptomatic acute reactive arthritis after an outbreak of salmonella. J Rheumatol 35: 1599-1602, 2008.

47. Simonet ML: Enterobacteria in reactive arthritis: Yersinia, Shigella, and Salmonella. Rev Rhum Engl Ed 66: 14S-18S; discussion 19S, 1999.

48. Tuompo R, Hannu T, Mattila L, Siitonen A and Leirisalo-Repo M: Reactive arthritis following Salmonella infection: A population-based study. Scand J Rheumatol 42: 196-202, 2013.

49. Zhang L, Zhang YJ, Chen J, Huang XL, Fang GS, Yang LJ Duan Y and Wang J: The association of HLA-B27 and Klebsiella pneumoniae in ankylosing spondylitis: A systematic review. Microb Pathog 117: 49-54, 2018

50. Rashid T and Ebringer A: Ankylosing spondylitis is linked to Klebsiella-the evidence. Clin Rheumatol 26: 858-864, 2007.

51. Tanimoto Y, Arikawa K and Nishikawa Y: Effect of diffusely adherent Escherichia coli strains isolated from diarrhoeal patients and healthy carriers on IL-8 secretion and tight junction barrier integrity of Caco-2 cells. Vet Immunol Immunopathol 152: 183-188, 2013.

52. Gill T, Asquith M, Rosenbaum JT and Colbert RA: The intestinal microbiome in spondyloarthritis. Curr Opin Rheumatol 27: $319-325,2015$

53. Mäki-Ikola O, Hill JL, Lahesmaa R, Toivanen A and Granfors K $\mathrm{IgG}$ and $\mathrm{Ig} \mathrm{A}$ antibody responses against porins in Yersinia-triggered reactive arthritis. Br J Rheumatol 31: 315-318, 1992.

54. Mäki-Ikola O, Lahesmaa R, Heesemann J, Merilahti-Palo R, Saario R, Toivanen A and Granfors K: Yersinia-specific antibodies in serum and synovial fluid in patients with Yersinia triggered reactive arthritis. Ann Rheum Dis 53: 535-539, 1994.

55. Mäki-Ikola O, Pulz M, Heesemann J, Lahesmaa R, Saario R, Toivanen A and Granfors K: Antibody response against 26 and 46 kilodalton released proteins of yersinia in yersinia triggered reactive arthritis. Ann Rheum Dis 51: 1247-1249, 1992.

56. Granfors K, Viljanen M, Tiilikainen A and Toivanen A: Persistence of IgM, IgG, and IgA antibodies to Yersinia in yersinia arthritis. J Infect Dis 141: 424-429, 1980.

57. Toivanen A, Lahesmaa-Rantala R, Vuento R and Granfors $K$ : Association of persisting IgA response with yersinia triggered reactive arthritis: A study on 104 patients. Ann Rheum Dis 46: 898-901, 1987

58. Ståhlberg TH, Heesemann J, Granfors K and Toivanen A Immunoblot analysis of $\mathrm{IgM}$, IgG, and $\mathrm{Ig} A$ responses to plasmid encoded released proteins of Yersinia enterocolitica in patients with or without yersinia triggered reactive arthritis. Ann Rheum Dis 48: 577-581, 1989.

59. Toivanen A, Granfors K, Lahesmaa-Rantala R, Leino R, Ståhlberg T and Vuento R: Pathogenesis of Yersinia-triggered reactive arthritis: Immunological, microbiological and clinical aspects. Immunol Rev 86: 47-70, 1985.

60. Louwen R and Hays JP: Is there an unrecognised role for Campylobacter infections in (chronic) inflammatory diseases? World J Clin Infect Dis 3: 58-69, 2013
61. Ajene AN, Fischer Walker CL and Black RE: Enteric pathogens and reactive arthritis: A systematic review of Campylobacter, salmonella and Shigella-associated reactive arthritis. J Health Popul Nutr 31: 299-307, 2013

62. Durán-Avelar MJ, Vibanco-Pérez N, Rodríguez-Ocampo AN, Peña-Virgen S and Zambrano-Zaragoza JF: Lymphoproliferative response to the $30-\mathrm{kDa}$ protein and a crude lysate from Salmonella typhimurium in patients with ankylosing spondylitis. Scand J Rheumatol 42: 232-234, 2013.

63. Zambrano-Zaragoza JF, de Jesus Durán-Avelar M, Rodríguez-Ocampo AN, García-Latorre E, Burgos-Vargas R, Dominguez-Lopez ML, Pena-Virgen S and Vibanco-Pérez N: The 30-kDa band from Salmonella typhimurium: IgM, IgA and IgG antibody response in patients with ankylosing spondylitis. Rheumatology (Oxford) 48: 748-754, 2009.

64. Dominguez-López ML, Burgos-Vargas R, Galicia-Serrano H Bonilla-Sánchez MT, Rangel-Acosta HH, Cancino-Diaz ME, Jiménez-Zamudio L, Granados J and García-Latorre E: IgG antibodies to enterobacteria $60 \mathrm{kDa}$ heat shock proteins in the sera of HLA-B27 positive ankylosing spondylitis patients. Scand J Rheumatol 31: 260-265, 2002.

65. Lahesmaa R, Skurnik M and Toivanen P: Molecular mimicry: Any role in the pathogenesis of spondyloarthropathies? Immunol Res 12: 193-208, 1993

66. Pacheco-Tena C, Alvarado De La Barrera C, López-Vidal Y, Vázquez-Mellado J, Richaud-Patin Y, Amieva RI, Llorente L, Martínez A, Zúñiga J, Cifuentes-Alvarado M and Burgos-Vargas R: Bacterial DNA in synovial fluid cells of patients with juvenile onset spondyloarthropathies. Rheumatology (Oxford) 40: 920-927, 2001.

67. Ekman P, Kirveskari J and Granfors K: Modification of disease outcome in Salmonella-infected patients by HLA-B27. Arthritis Rheum 43: 1527-1534, 2000.

68. Ekman P, Saarinen M, He Q, Gripenberg-Lerche C, Grönberg A, Arvilommi H and Granfors K: HLA-B27-transfected (Salmonella permissive) and HLA-A2-transfected (Salmonella nonpermissive) human monocytic U937 cells differ in their production of cytokines. Infect Immun 70: 1609-1614, 2002.

69. Saarinen M, Ekman P, Ikeda M, Virtala M, Grönberg A, Yu DT, Arvilommi $\mathrm{H}$ and Granfors $\mathrm{K}$ : Invasion of Salmonella into human intestinal epithelial cells is modulated by HLA-B27. Rheumatology (Oxford) 41: 651-657, 2002.

70. Sartor RB: Importance of intestinal mucosal immunity and luminal bacterial cell wall polymers in the aetiology of inflammatory joint diseases. Baillieres Clin Rheumatol 3: 223-245, 1989.

71. Salas-Cuestas F, Bautista-Molano W, Bello-Gualtero JM, Arias I, Castillo DM, Chila-Moreno L, Valle-Oñate R, Herrera D and Romero-Sánchez C: Higher levels of secretory IgA are associated with low disease activity index in patients with reactive arthritis and undifferentiated spondyloarthritis. Front Immunol 8: 476, 2017.

72. Granfors K and Toivanen A: IgA-anti-yersinia antibodies in yersinia triggered reactive arthritis. Ann Rheum Dis 45: 561-565, 1986.

73. Wendling D, Didier JM and Seilles E: Serum secretory immunoglobulins in ankylosing spondylitis. Clin Rheumatol 15: 590-593, 1996.

74. Franssen MJ, van de Putte LB and Gribnau FW: IgA serum levels and disease activity in ankylosing spondylitis: A prospective study. Ann Rheum Dis 44: 766-771, 1985.

75. Cowling P, Ebringer R and Ebringer A: Association of inflammation with raised serum $\operatorname{IgA}$ in ankylosing spondylitis. Ann Rheum Dis 39: 545-549, 1980.

76. Rashid T, Wilson C and Ebringer A: The link between ankylosing spondylitis, Crohn's disease, Klebsiella, and starch consumption. Clin Dev Immunol 2013: 872632, 2013.

77. Eastmond CJ, Willshaw HE, Burgess SE, Shinebaum R, Cooke EM and Wright V: Frequency of faecal Klebsiella aerogenes in patients with ankylosing spondylitis and controls with respect to individual features of the disease. Ann Rheum Dis 39: 118-123, 1980.

78. Hunter T, Harding GK, Kaprove RE and Schroeder ML: Fecal carriage of various Klebsiella and Enterobacter species in patients with active ankylosing spondylitis. Arthritis Rheum 24: 106-108, 1981

79. Ebringer A and Ghuloom M: Ankylosing spondylitis, HLA-B27, and klebsiella: Cross reactivity and antibody studies. Ann Rheum Dis 45: 703-704, 1986.

80. Puccetti A, Dolcino M, Tinazzi E, Moretta F, D'Angelo S, Olivieri I and Lunardi C: Antibodies directed against a peptide epitope of a klebsiella pneumoniae-derived protein are present in ankylosing spondylitis. PLoS One 12: e0171073, 2017

81. Smith GW, Blackwell CC and Nuki G: Faecal flora in spondyloarthropathy. Br J Rheumatol 36: 850-854, 1997. 
82. Mäki-Ikola O, Penttinen M, Von Essen R, Gripenberg-Lerche C, Isomäki $\mathrm{H}$ and Granfors $\mathrm{K}$ : IgM, IgG and IgA class enterobacterial antibodies in serum and synovial fluid in patients with ankylosing spondylitis and rheumatoid arthritis. Br J Rheumatol 36: 1051-1053, 1997.

83. Mäki-Ikola O, Leirisalo-Repo M, Turunen U and Granfors K Association of gut inflammation with increased serum $\operatorname{Ig} \mathrm{A}$ class Klebsiella antibody concentrations in patients with axia ankylosing spondylitis (AS): Implication for different aetiopathogenetic mechanisms for axial and peripheral AS? Ann Rheum Dis 56: 180-183, 1997.

84. Shenkman L and Bottone EJ: Antibodies to Yersinia enterocolitica in thyroid disease. Ann Intern Med 85: 735-739, 1976.
85. Benvenga $\mathrm{S}$ and Guarneri F: Molecular mimicry and autoimmune thyroid disease. Rev Endocr Metab Disord 17: 485-498, 2016.

86. Hansen PS, Wenzel BE, Brix TH and Hegedüs L: Yersinia enterocolitica infection does not confer an increased risk of thyroid antibodies: Evidence from a Danish twin study. Clin Exp Immunol 146: 32-38, 2006.

87. Strieder TGA. 'The Amsterdam autoimmune thyroid disease cohort', $\mathrm{PhD}$ thesis, https://dare.uva.nl/search?identifier $=\mathrm{d} 4307$ adf-2a19-462f-8211-7922dcc988e0.

88. Bliddal S, Nielsen $\mathrm{CH}$ and Feldt-Rasmussen U: Recent advances in understanding autoimmune thyroid disease: The tallest tree in the forest of polyautoimmunity. F1000res 6: 1776, 2017. 